PREPARED FOR THE U.S. DEPARTMENT OF ENERGY, UNDER CONTRACT DE-AC02-76CH03073

PPPL-3909

PPPL-3909

UC-70

Analytical and Numerical Studies of the Complex Interaction of a Fast Ion Beam Pulse with a Background Plasma

by

Igor D. Kaganovich, Edward A. Startsev, and Ronald C. Davidson

November 2003

$N_{\substack{\text { PRInCETOn PLASMA } \\ \text { PHYSIES LABORATORY }}}^{D}$

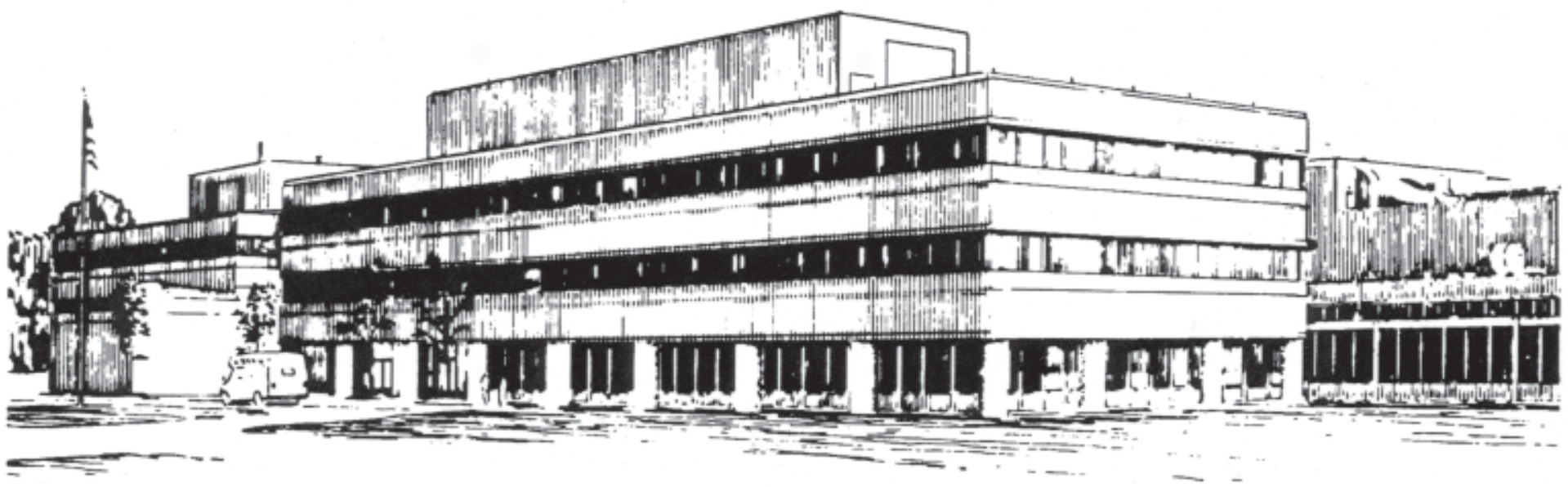

PRINCETON PLASMA PHYSICS LABORATORY PRINCETON UNIVERSITY, PRINCETON, NEW JERSEY 


\section{PPPL Reports Disclaimer}

This report was prepared as an account of work sponsored by an agency of the United States Government. Neither the United States Government nor any agency thereof, nor any of their employees, makes any warranty, express or implied, or assumes any legal liability or responsibility for the accuracy, completeness, or usefulness of any information, apparatus, product, or process disclosed, or represents that its use would not infringe privately owned rights. Reference herein to any specific commercial product, process, or service by trade name, trademark, manufacturer, or otherwise, does not necessarily constitute or imply its endorsement, recommendation, or favoring by the United States Government or any agency thereof. The views and opinions of authors expressed herein do not necessarily state or reflect those of the United States Government or any agency thereof.

\section{Availability}

This report is posted on the U.S. Department of Energy's Princeton Plasma Physics Laboratory Publications and Reports web site in Fiscal Year 2004. The home page for PPPL Reports and Publications is: http://www.pppl.gov/pub_report/

DOE and DOE Contractors can obtain copies of this report from:

U.S. Department of Energy

Office of Scientific and Technical Information

DOE Technical Information Services (DTIS)

P.O. Box 62

Oak Ridge, TN 37831

Telephone: (865) 576-8401

Fax: (865) 576-5728

Email: reports@adonis.osti.gov

This report is available to the general public from:

National Technical Information Service

U.S. Department of Commerce

5285 Port Royal Road

Springfield, VA 22161

Telephone: $1-800-553-6847$ or

(703) $605-6000$

Fax: (703) 321-8547

Internet: http://www.ntis.gov/ordering.htm 


\title{
Analytical and Numerical Studies of the Complex Interaction of a Fast Ion Beam Pulse with a
}

\section{Background Plasma}

\author{
Igor D. Kaganovich, Edward A. Startsev, Ronald C. Davidson \\ Plasma Physics Laboratory, Princeton University, Princeton, New Jersey 08543, USA
}

\begin{abstract}
Plasma neutralization of an intense ion beam pulse is of interest for many applications, including plasma lenses, heavy ion fusion, high energy physics, etc. Comprehensive analytical, numerical and experimental studies are underway to investigate the complex interaction of a fast ion beam with a background plasma. The positively charged ion beam attracts plasma electrons, and as a result the plasma electrons have a tendency to neutralize the beam charge and current. A suite of particle-in-cell codes has been developed to study the propagation of an ion beam pulse through the background plasma. For quasi-steady-state propagation of the ion beam pulse, an analytical theory has been developed using the assumption of long charge bunches and conservation of generalized vorticity. The analytical results agree well with the results of the numerical simulations. The visualization of the data obtained in the numerical simulations shows complex collective phenomena during beam entry into and exit from the plasma.
\end{abstract}

\section{Introduction}

Neutralization of the ion beam charge and current by a background plasma is an important issue for many applications involving the transport of positive charges in plasma, including heavy ion inertial fusion [1], positrons for electron-positron colliders [2], high-density laser-produced proton beams for the fast ignition of inertial confinement fusion targets [3], etc. In these applications, plasma is used to reduce the high self-electric and self-magnetic fields of the beam.

The case where the beam propagates through a cold plasma, with the plasma density large compared with the beam density, can be studied by the use of linear perturbation theory [4]. In this paper, we focus on the nonlinear case where the plasma density has an arbitrary value compared with the beam density. The transport of stripped, pinched ion beams has also been discussed in [1], where the assumptions of current and charge neutrality were made to determine self-consistent solutions for the electric and magnetic fields. Rosenbluth, et al., have considered the equilibrium of an isolated, charge-neutralized, self-pinched ion beam pulse in the absence of background plasma [5]. In contrast, we consider here the case where "fresh" plasma is always available in front of the beam, and there are no electrons co-moving with the beam.

The electron response frequency is of order the electron plasma frequency, $\omega_{p}=\left(4 \pi n_{p} e^{2} / m_{e}\right)^{1 / 2}$, where $n_{p}$ is the background plasma density. For heavy ion fusion applications, the ion pulse propagation time through the chamber is much longer than the inverse electron plasma frequency $\omega_{p}^{-1}$. Therefore, a beam-plasma quasi-steady state forms during beam propagation. The steady-state propagation (in the beam frame) of an ion beam pulse through a background plasma has been investigated in Refs. [6-9].

In recent calculations [6,7], we studied the nonlinear quasi-equilibrium properties of an intense ion beam pulse propagating through a cold background plasma, assuming that the beam pulse duration $\tau_{b}$ is much longer than the inverse electron plasma frequency, i.e., $\omega_{p} \tau_{b} \gg 1$. In a related study [8], we extended the previous results to general values of the parameter $\omega_{p} \tau_{b}$. Here, complex collective phenomena are found during beam entry into and exit from the plasma.

\section{Basic equations for ion beam pulse propagation in background plasma}

Treating the beam ions and plasma ions as infinitely massive, the electron momentum equation together with Maxwell's equations comprise a complete system of equations describing the electron response to a propagating ion beam pulse. The electron momentum equation is given by,

$\frac{d \mathbf{p}_{e}}{d t}=-e\left(\mathbf{E}+\frac{1}{c} \mathbf{V}_{e} \times \mathbf{B}\right)$,

where $-e$ is the electron charge, $\mathbf{V}_{e}$ is the electron velocity, $\mathbf{p}_{e}=\gamma_{e} m_{e} \mathbf{V}_{e}$ is the electron momentum, $m_{e}$ is the electron rest mass, and $\gamma_{e}$ is the relativistic mass factor. Maxwell's equations for the self-generated electric and magnetic fields, $\mathbf{E}$ and $\mathbf{B}$, are given by

$$
\begin{aligned}
\nabla \times \mathbf{B} & =\frac{4 \pi e}{c}\left(Z_{b} n_{b} \mathbf{V}_{b}-n_{e} \mathbf{V}_{e}\right)+\frac{1}{c} \frac{\partial \mathbf{E}}{\partial t}, \\
\nabla \times \mathbf{E} & =-\frac{1}{c} \frac{\partial \mathbf{B}}{\partial t},
\end{aligned}
$$

where $\mathbf{V}_{\mathbf{b}}$ is the ion beam flow velocity, $n_{e}$ and $n_{b}$ are the number densities of the plasma electrons and beam ions, respectively (the background plasma is uniform with density $n_{p}$, and far away from the beam $n_{e} \rightarrow n_{p}$ ), and $Z_{b}$ is the ion beam charge state. The plasma ions are assumed to remain stationary with $\boldsymbol{V}_{\boldsymbol{i}}=0$ and $n_{i}=n_{p}$. In reality the plasma ions tend to be expelled by the ion beam self-electric field, but for short ion pulses, the plasma ions do not have time to move. The assumption of immobile plasma ions is valid for sufficiently short ion pulses with 
$2 l_{b}<r_{b} \sqrt{M / m_{e}}$ [6]. Here, $r_{b}$ and $2 l_{b}$ are the ion beam radius and length, respectively, and $M$ is the plasma ion mass.

Note that considerable simplification can be achieved by applying the conservation of generalized vorticity $\boldsymbol{\Omega}$ [6]. If $\boldsymbol{\Omega}$ is initially equal to zero ahead of the beam, and all streamlines inside of the beam originate from the region ahead of the beam, then $\boldsymbol{\Omega}$ remains equal to zero everywhere, i.e.,

$$
\boldsymbol{\Omega} \equiv \nabla \times \mathbf{p}_{e}-\frac{e}{c} \mathbf{B}=0 .
$$

If most electrons are dragged along with the beam and originate from the region of large magnetic field, the situation may be different $[5,9]$. a)
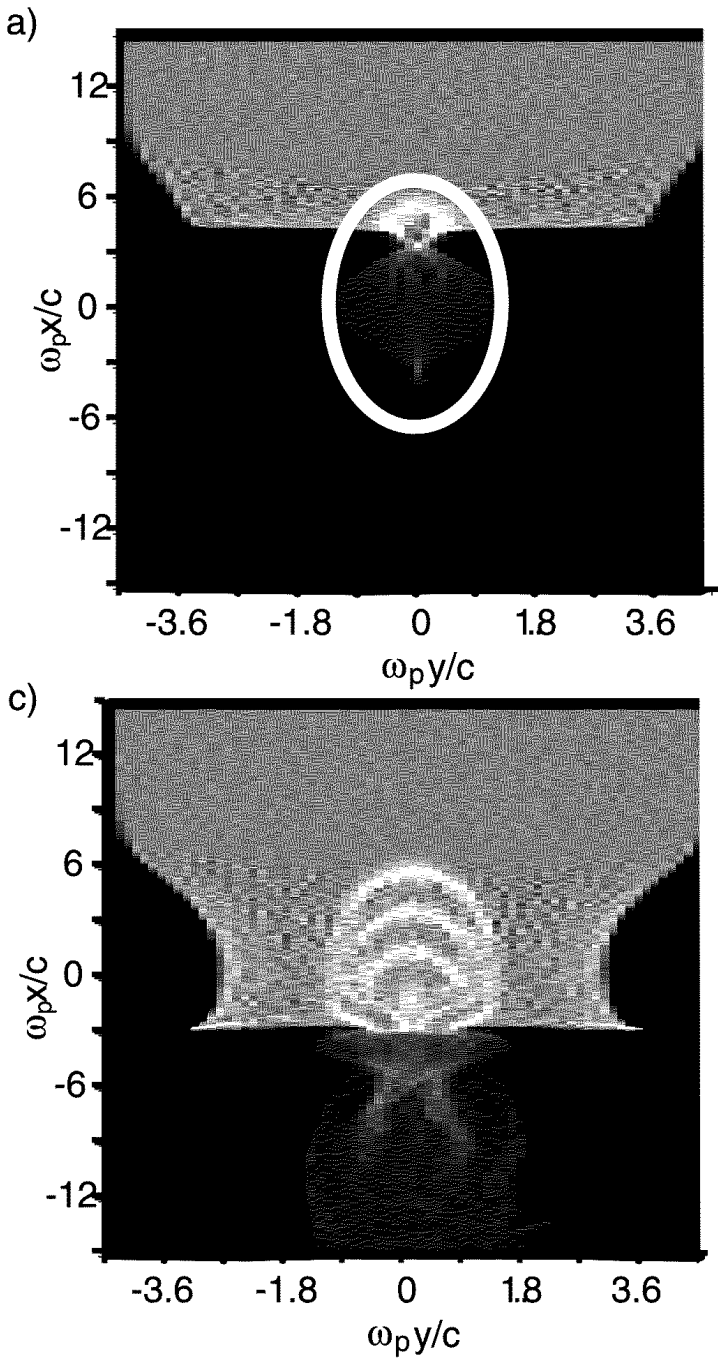

b)
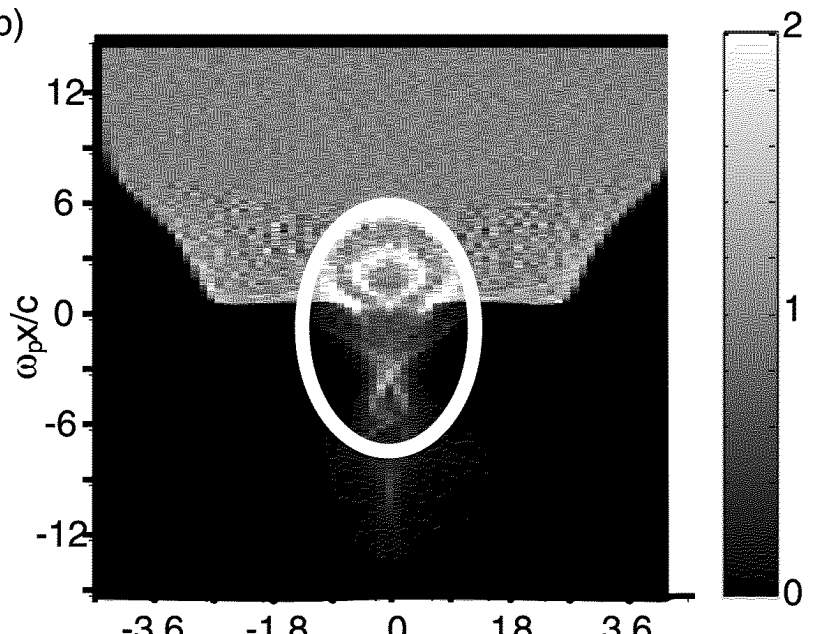

d)

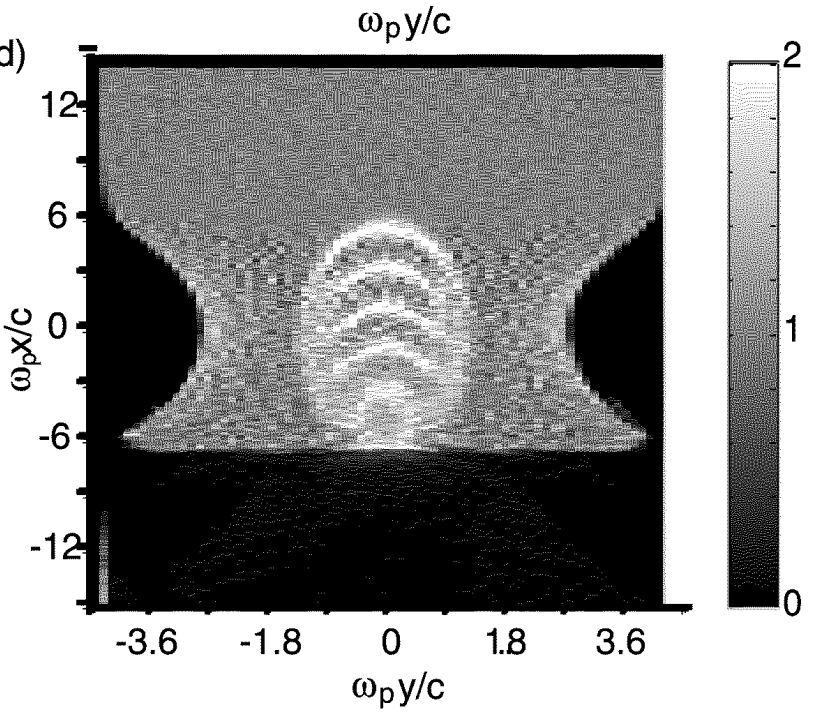

Figure 1. Beam entry into the background plasma. The beam propagates in the x-direction. Shown in the figure are color plots of the normalized electron density $\left(n_{e} / n_{p}\right)$ obtained in particle-in-cell simulations. The beam velocity is $V_{b}=0.5 c$, and the beam density is $n_{b}=0.5 n_{p}$. The beam pulse dimensions correspond to radius $r_{b}=1.5 \mathrm{c} / \omega_{p}$ and half length $l_{b}=7.5 \mathrm{c} / \omega_{p}$ (the beam pulse duration $\tau_{b}$ is long compared with the inverse plasma frequency $\omega_{p} \tau_{b}=30$ ); the beam density profile is flattop with smooth edges at $20 \%$ of the beam size; see Ref. [4] for more details. Shown in the figure are contours at four different times after the beam enters the plasma at successive time intervals of $3 \pi / \omega_{p}$. White contours show the position of the edges of the ion beam. 
a)
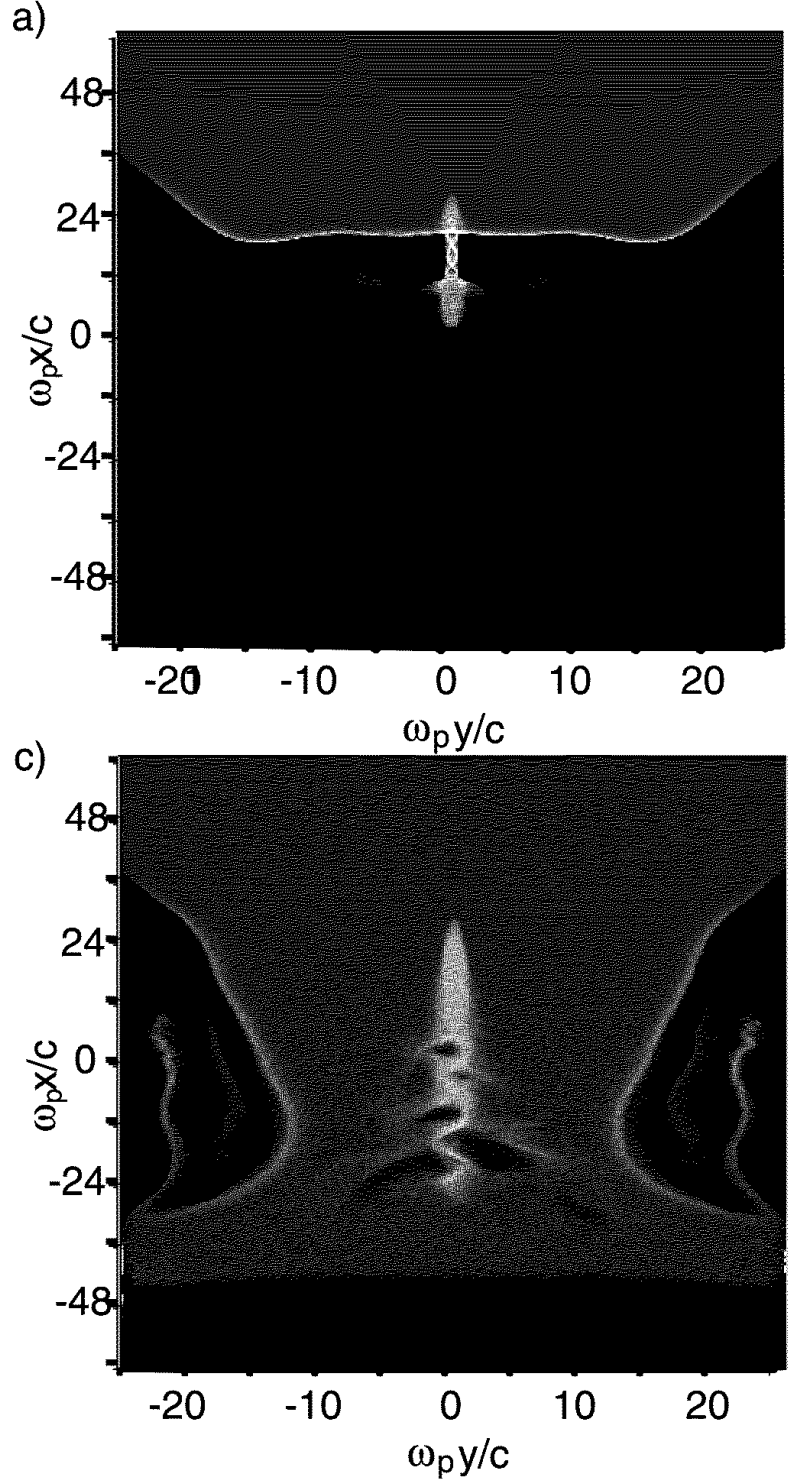

b)
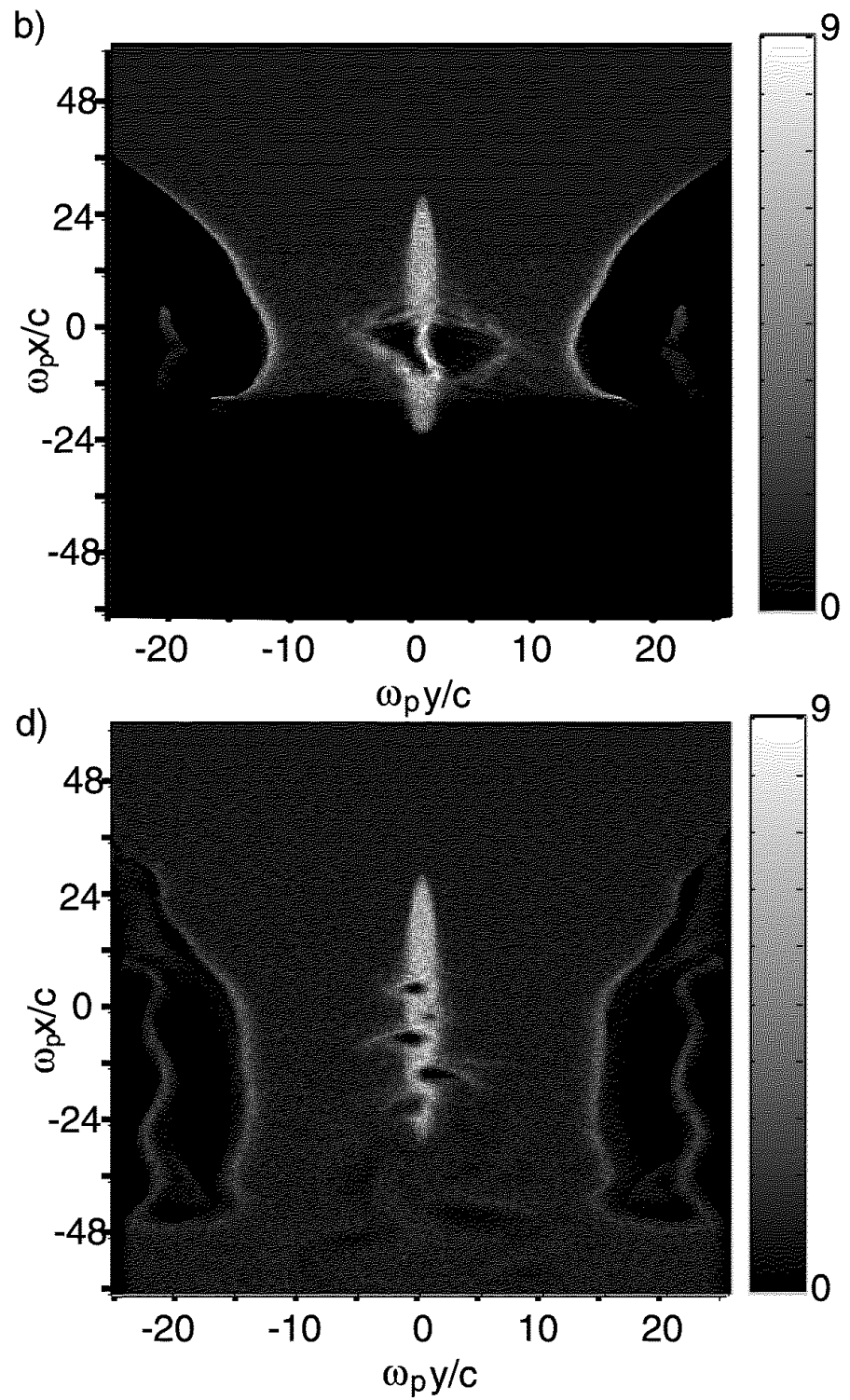

Figure 2. Beam entry into the background plasma similar to Fig.1, but for a more intense ion beam. The beam density is $n_{b}=5 n_{p}$; the beam pulse dimensions correspond to radius $r_{b}=1.5 \mathrm{c} / \omega_{p}$, and half length $l_{b}=30 \mathrm{c} / \omega_{p}$ (the beam pulse duration $\tau_{b}$ is long compared with the inverse plasma frequency $\omega_{p} \tau_{b}=120$ ). Shown in the figure are contours at four different times after the beam enters the plasma at successive time intervals of $20 \pi / \omega_{p}$. 
a)

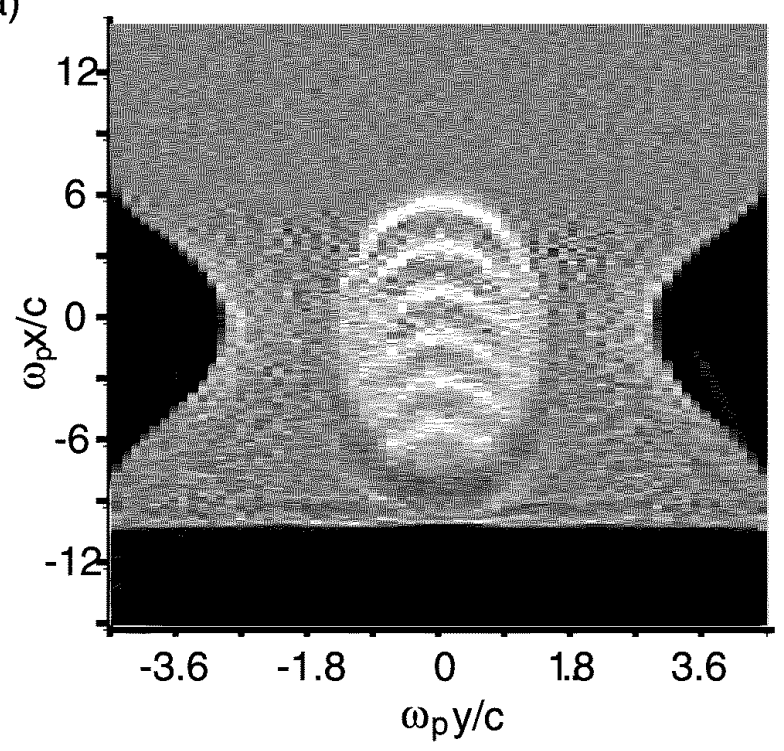

b)

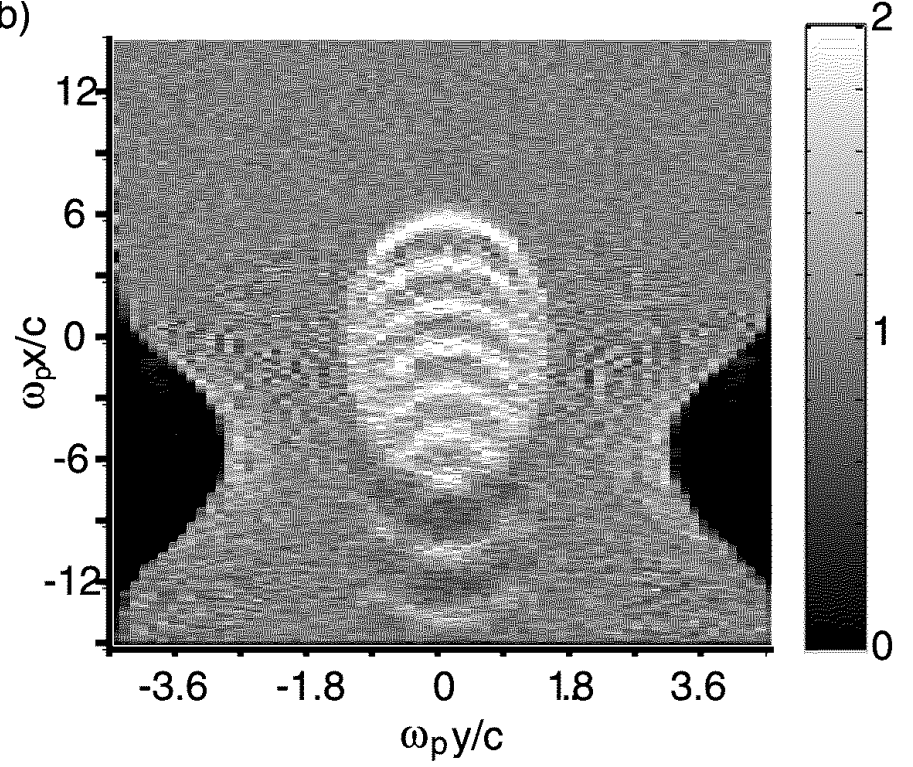

Figure 3. Beam entry into the background plasma for the same conditions as in Fig.1 but at later times. Figure 3(a) is taken at a time interval $3 \pi / \omega_{p}$ later than Fig. 1(d), and Fig. 3(b) is taken at a time interval $30 \pi / \omega_{p}$ later than Fig. 3(a). Note that the hole velocity in the beam frame is approximately $6 c / 30 \pi \approx c / 16$ or $1 / 8^{\text {th }}$ of the beam velocity.

\section{Collective phenomena during beam entry into and exit from the plasma}

In plasma focusing schemes, the ion beam pulse after acceleration enters the plasma for focusing or transport purposes. It is important to access the transition to steadystate propagation in the background plasma [1,2]. As the intense ion beam enters the plasma, the plasma electrons readily move in the strong electric and magnetic fields. Because the plasma electron density is comparable with the ion beam density, the plasma electrons can generate current and space charge as high as the ion beam current and charge. As a result, the ion-beam self fields change significantly in the plasma. Consequently, the electron motion during the entry of the intense beam into the plasma exhibits highly complex collective behavior as shown in Figs. 1-4. The simulations presented in Figs. 1-4 are obtained using the edPIC particle-in-cell code [10]. For fast intense ion beams, the self-magnetic field $\mathbf{B}$ of the beam ions affects considerably the electron motion. For the parameters in Figs. 1 and 2, the electron cyclotron frequency $\omega_{c}=e B / m_{e} c$ is comparable with the electron plasma frequency $\omega_{p}$. As a result, the electrons penetrate into the beam initially only in the beam center, where the magnetic field is small. Therefore, when the beam density is increased relative to the background plasma density, $\omega_{c}$ increases compared with $\omega_{p}$, thereby increasing the effect of the magnetic field on the electron dynamics (compare Figs. 1 and 2). Figure 2 shows the development of hose-like structures and electron holes during the beam entry, which are absent in Fig.1. Because the ion beam collects electrons predominantly in the transverse direction, large electron holes (absence of electrons) appear near the plasma boundaries. In Fig.2, the electron holes 'break' after some time, and an electron stream moves from the "bottom" of the hole upward with a speed even larger than the beam speed. In contrast, the holes in Fig.1 do not break, but trail along beside the beam, slowly lagging behind the beam with velocity approximately $V_{b} / 8$, as can be seen in Fig.3.

Figure 4 shows the excitation of plasma waves during beam exit from the plasma. In contrast to steady-state propagation, where the plasma waves establish a stationary stripe-like pattern $[4,6,8]$, after the beam exits the plasma the plasma waves form a nonstationary periodic pattern resembling butterfly-wing motion.

In summary, steady-state ion beam propagation through a background plasma has been described in detail in previous publications [4-8]. The analytical results agree well with the results of PIC numerical simulations for ion beam charge and current neutralization for the case of steady-state ion beam propagation in a background plasma. In contrast to steady-state ion beam propagation, the visualization of the time-dependent data obtained in the numerical simulations presented here shows largely unexplored, complex collective phenomena during beam entry into and exit from the plasma. Further visualization material is also available on the website [11].

Acknowledgments: This research was supported by the U.S. Department of Energy Office of Fusion Energy Sciences and the Office of High Energy Physics. 
a)

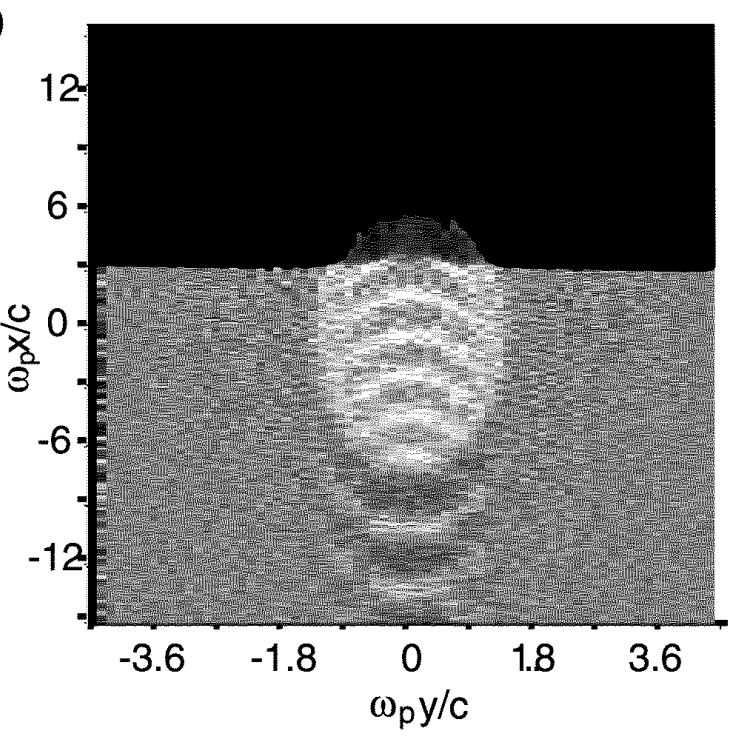

c)

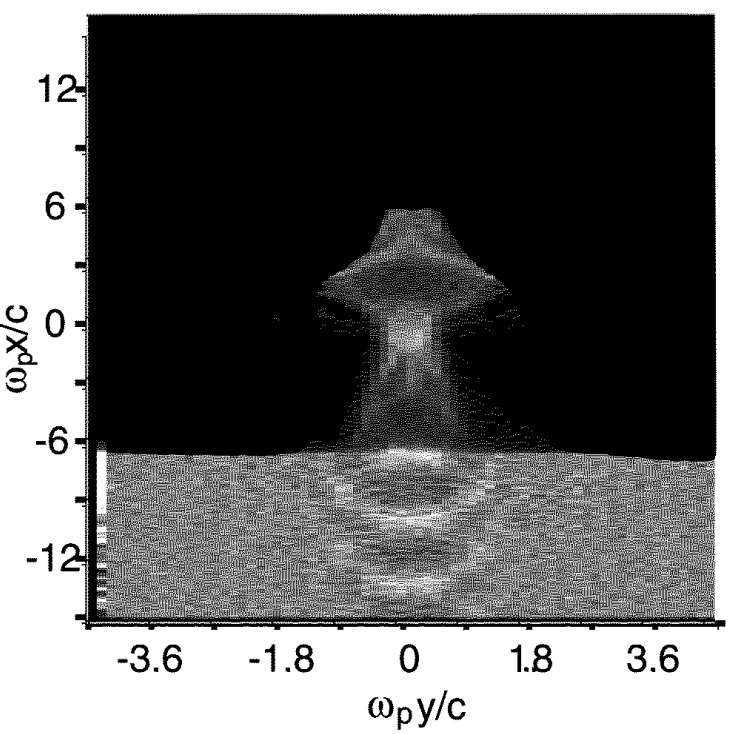

b)

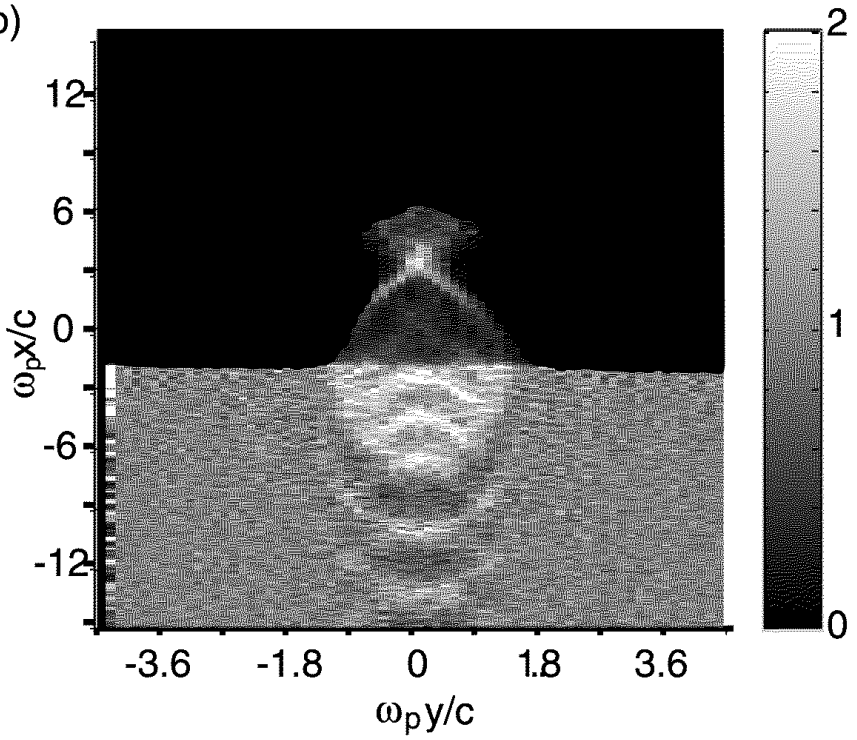

d)

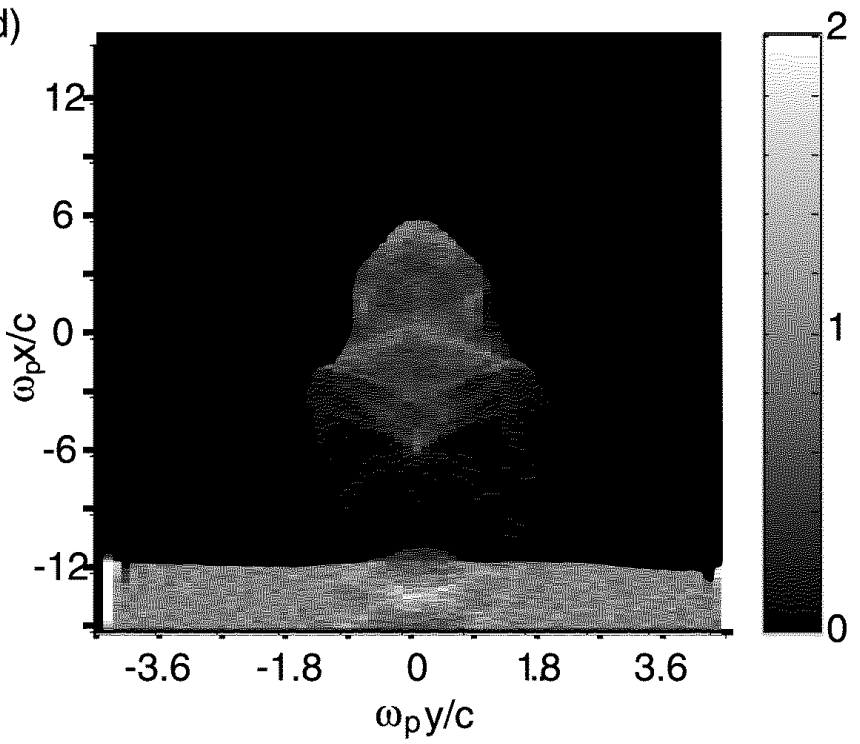

Figure 4. Beam exit from the background plasma for the same parameters as in Figs.1and 3, but at later times. Figure 4(a) is taken at a time interval $78 \pi / \omega_{p}$ after Fig. 3(b), and the subsequent figures are taken at successive time intervals of $4 \pi / \omega_{p}$.

\section{References}

[1] Hahn, K., and Lee, E. P., J. Fusion Engineering and Design 32-33, 417 (1996).

[2] Hogan, M.J. et al., Phys. Rev. Lett. 90, 205002 (2003).

[3] Krushelnik, K. et al., IEEE Trans. Plasma Sci. 28, 1185 (2000).

[4] Chen, P., Dawson, J.M., Huff, R. W. and Katsouleas, T., Phys. Rev. Lett. 51, 693 (1985).

[5] Rosenbluth, M., Lee, E.P. and Briggs, R., private communication (2001).

[6] Kaganovich, I. D., Shvets, G., Startsev, E. A. and Davidson, R. C., Physics of Plasmas 8, 4180 (2001).
[7] Kaganovich, I. D., Startsev, E. A. and Davidson, R. C., Laser and Particle Beams 20, 497 (2002).

[8] Kaganovich, I. D., Startsev, E. A. and Davidson, R. C., Proc. 2003 Particle Accelerator Conference; http://warrior.lbl.gov:7778/pacfiles/papers/THURSDAY /AM POSTER/RPAG039/RPAG039.PDF

[9] Welch, D. R. et al., Phys. Plasmas 9, 2344 (2002).

[10] Startsev, E. A. and McKinstrie, C. J., Phys. Plasmas, 10, 2552 (2003).

[11] High Intensity Particle Beams and Nonneutral Plasma, Division, Plasma Physics Laboratory, Princeton University; http://nonneutral.pppl.gov/. 


\section{External Distribution}

Plasma Research Laboratory, Australian National University, Australia

Professor I.R. Jones, Flinders University, Australia

Professor João Canalle, Instituto de Fisica DEQ/IF - UERJ, Brazil

Mr. Gerson O. Ludwig, Instituto Nacional de Pesquisas, Brazil

Dr. P.H. Sakanaka, Instituto Fisica, Brazil

The Librarian, Culham Laboratory, England

Mrs. S.A. Hutchinson, JET Library, England

Professor M.N. Bussac, Ecole Polytechnique, France

Librarian, Max-Planck-Institut für Plasmaphysik, Germany

Jolan Moldvai, Reports Library, Hungarian Academy of Sciences, Central Research Institute for Physics, Hungary

Dr. P. Kaw, Institute for Plasma Research, India

Ms. P.J. Pathak, Librarian, Institute for Plasma Research, India

Ms. Clelia De Palo, Associazione EURATOM-ENEA, Italy

Dr. G. Grosso, Instituto di Fisica del Plasma, Italy

Librarian, Naka Fusion Research Establishment, JAERI, Japan

Library, Laboratory for Complex Energy Processes, Institute for Advanced Study, Kyoto University, Japan

Research Information Center, National Institute for Fusion Science, Japan

Dr. O. Mitarai, Kyushu Tokai University, Japan

Dr. Jiangang Li, Institute of Plasma Physics, Chinese Academy of Sciences, People's Republic of China

Professor Yuping Huo, School of Physical Science and Technology, People's Republic of China

Library, Academia Sinica, Institute of Plasma Physics, People's Republic of China

Librarian, Institute of Physics, Chinese Academy of Sciences, People's Republic of China

Dr. S. Mirnov, TRINITI, Troitsk, Russian Federation, Russia

Dr. V.S. Strelkov, Kurchatov Institute, Russian Federation, Russia

Professor Peter Lukac, Katedra Fyziky Plazmy MFF UK, Mlynska dolina F-2, Komenskeho Univerzita, SK-842 15 Bratislava, Slovakia

Dr. G.S. Lee, Korea Basic Science Institute, South Korea

Institute for Plasma Research, University of Maryland, USA

Librarian, Fusion Energy Division, Oak Ridge National Laboratory, USA

Librarian, Institute of Fusion Studies, University of Texas, USA

Librarian, Magnetic Fusion Program, Lawrence Livermore National Laboratory, USA

Library, General Atomics, USA

Plasma Physics Group, Fusion Energy Research Program, University of California at San Diego, USA

Plasma Physics Library, Columbia University, USA

Alkesh Punjabi, Center for Fusion Research and Training, Hampton University, USA

Dr. W.M. Stacey, Fusion Research Center, Georgia Institute of Technology, USA

Dr. John Willis, U.S. Department of Energy, Office of Fusion Energy Sciences, USA

Mr. Paul H. Wright, Indianapolis, Indiana, USA 
The Princeton Plasma Physics Laboratory is operated by Princeton University under contract with the U.S. Department of Energy.

\author{
Information Services \\ Princeton Plasma Physics Laboratory \\ P.O. Box 451 \\ Princeton, NJ 08543
}

Phone: 609-243-2750

Fax: 609-243-2751

e-mail: pppl_info@pppl.gov

Internet Address: http://www.pppl.gov 